\title{
BMJ Open Patterns of smoking initiation during adolescence and young adulthood in South-West China: findings of the National Nutrition and Health Survey (2010-2012)
}

Qiang Zhang, ${ }^{1,2}$ Bin Yu, ${ }^{2}$ Xinguang Chen, ${ }^{2}$ Deepthi S Varma, ${ }^{2}$ Juanjuan $\mathrm{Li}^{1}{ }^{1}$ Jiang Zhao, ${ }^{1}$ Yuan Ruan, ${ }^{1}$ Xingmeng Han, ${ }^{3}$ Xiangdong Min, ${ }^{1}$ Zhitao Liu ${ }^{1}$

To cite: Zhang Q, Yu B, Chen X, et al. Patterns of smoking initiation during adolescence and young adulthood in SouthWest China: findings of the National Nutrition and Health Survey (2010-2012). BMJ Open 2018;8:e019424. doi:10.1136/ bmjopen-2017-019424

- Prepublication history for this paper is available online. To view these files, please visit the journal online (http://dx.doi. org/10.1136/bmjopen-2017019424).

Received 1 September 2017 Revised 7 March 2018 Accepted 6 April 2018
Check for updates

${ }^{1}$ Department of Nutrition and Food Hygiene, Yunnan center for disease control and prevention, Kunming, China

${ }^{2}$ Department of Epidemiology, University of Florida, Gainesville, Florida, USA

${ }^{3}$ School of Public Health, Kunming Medical University, Kunming, China

Correspondence to

Dr Zhitao Liu;

counterstriker_zq@163.com

\section{ABSTRACT}

Objective This study aims to understand the age patterns of smoking initiation during adolescence and young adulthood in South-West China, where the prevalence of tobacco use is reported as the highest in the country. Design A cross-sectional study.

Setting The data were derived from the China National Nutrition and Health Survey in Yunnan Province, SouthWest China (2010-2012).

Participants A total of 4801 participants aged 15-65 years were included.

Primary outcome measures A survival model was used to estimate the hazard of smoking initiation by age and log-rank test was used to compare the hazard curves across subgroups (men/women, urban/rural, Han Chinese/ ethnic minority)

Results The prevalence of current smoking among men and women were $60.4 \%(95 \% \mathrm{Cl} 58.2 \%$ to $62.6 \%)$ and $5.1 \%(95 \% \mathrm{Cl} 4.3 \%$ to $5.9 \%)$, respectively. Smoking was more prevalent among men and women of lower education and less income, as well as rural and ethnic minority women. Among the current smokers, cigarette $(80.7 \%)$ was the most commonly used tobacco product, followed by waterpipe $(10.8 \%)$ and pipe tobacco $(8.5 \%)$. The hazards of smoking initiation were low for both men and women before the age of 15 years (1\% for men and $0.05 \%$ for women); and the hazards increased quickly from age 15 years and peaked at 19years $(21.5 \%$ for men and $1.0 \%$ for women). Rural and ethnic minority women were at higher risk of smoking initiation than their counterparts between 15 years and 19 years of age $\left(\chi^{2}=44.8, p<0.01 ; \chi^{2}=165.2, p<0.01\right)$ and no such difference was found in men.

Conclusions Findings of this study underscore the importance to implement tobacco prevention interventions among older teens and young adults in South-West China, especially for rural and ethnic minority women.

\section{INTRODUCTION}

Tobacco use is a leading preventable cause of morbidity and mortality across the globe. ${ }^{1}$ As the world's largest producer and consumer
Strengths and limitations of this study

- This is the first study to examine the hazards of smoking initiation by age during adolescence and young adulthood in South-West China.

- The age, sex, and ethnic and cultural disparities in the hazards of smoking initiation revealed in this study are needed to develop targeted preventive interventions.

- As the sample was only from six counties in Yunnan Province, caution is needed to generalise the results to other places.

of tobacco, China has more than 300 million smokers and 740 million non-smokers exposed to secondhand smoke. ${ }^{2}$ In 2010, an estimated 1 million deaths were attributed to tobacco smoking alone in China. ${ }^{3}$ This highlights the significance of implementing effective and culture-specific tobacco control interventions in China.

Persistent tobacco control efforts over the past 20 years have resulted in significant declines in tobacco smoking among Chinese adults. ${ }^{45}$ However, this decline is not uniform across various regions and among different population subgroups. For example, in 2010, an estimated $26.2 \%$ of adults in East China were current smokers, whereas the prevalence was $30.4 \%$ in West China. ${ }^{6}$ A study conducted in North-East China found that the prevalence of current smoking among women was as high as $9.4 \%$, roughly four times that of the Chinese national average for women. ${ }^{6}$ Moreover, some studies have suggested that smoking might be more prevalent among the ethnic minority than Han Chinese. ${ }^{89}$ Similarly, a recent study from the USA has also shown a significant difference in cigarette smoking prevalence across different 
races such as: whites $(24.9 \%)$ and Asians (10.9\%). ${ }^{10} \mathrm{~A}$ study conducted by Chen et al on cigarette smoking in a multiethnic population reported significantly higher hazards of smoking initiation for white adolescents than their Asian counterparts. ${ }^{11}$ Findings from this study implied that the disparity in smoking prevalence among adults might be attributed to the differences in smoking initiation during adolescence. ${ }^{11}$ Studies from China and other countries have also confirmed that smoking initiation at a young age strongly predicts future smoking patterns including daily smoking, smoking intensity and difficultly quitting. ${ }^{12-14}$ Therefore, planning and implementing early intervention strategies to prevent smoking initiation among adolescents is one of the most promising strategies for tobacco control. ${ }^{15}$

Adolescence represents a high-risk period for smoking initiation and tobacco use behaviour development. After the first puff, many adolescents continue to experiment with tobacco products, leading to more regular use and ultimately nicotine addiction. ${ }^{16}$ This transition from smoking initiation to daily smoking can happen quickly or can take years. ${ }^{17} 18$ Ideally, smoking prevention programmes should begin before the period of maximum risk of smoking initiation and continue until after the maximum risk has ended. Although the average age of smoking initiation among smokers in China is approximately 21 years, most of them have started smoking long before that age. ${ }^{419}$ By using the survival model, Chen et al studied the hazard of smoking initiation by age among junior middle school students in Wuhan, China and reported a sharp increase after 12 years of age. ${ }^{14}$ New studies indicate that individuals start smoking at younger and younger ages. ${ }^{20}$ Therefore, exploring the current age patterns of smoking initiation is essential to develop effective targeted tobacco prevention strategies.

Yunnan province is located in South-West China and has the most ethnic minorities. Yunnan province is also the main production and consumption hub for tobacco products, such as cigarettes, waterpipe and pipe tobacco. This study investigates the age patterns of cigarette smoking initiation in South-West China, as well as the disparities in sex, ethnicity and residence.

\section{METHODS}

\section{Study design, setting and participants}

This paper analysed data from the 2010-2012 China National Nutrition and Health Survey in Yunnan Province. Participants for this study were recruited using a multistratified cluster sampling method from six counties in Yunnan Province (Panlong, Gejiu, Luxi, Menglian, Ninglan and Shuifu). These six counties differ from each other in their geographical regions within the province, population sizes, ethnic groups and levels of economic development. These research sites adequately represent South-West China, and highlight the urban-rural differences.
From each of the above selected six counties, three townships were randomly selected followed by the random selection of three villages from each township. Next, from each village, 75 households were randomly selected and all members over 15 years of age from each of the selected households were invited to participate in the survey. A total of 4801 participants completed the survey, with a response rate of $97 \%$. Signed informed consent was obtained from all the participants before the survey.

\section{Patient and public involvement}

This study is a population-based survey study. Patients and public were not involved.

\section{Measures}

Current smokers were defined as individuals who reportedly smoke any tobacco product currently. Lifetime smokers were defined as individuals who have a lifetime history of smoking. ${ }^{21}$ Non-smokers were defined as individuals who had never smoked. Age of smoking initiation was defined as the age at which a participant first puffed on any tobacco product including cigarette, pipe tobacco and waterpipe. For those who never smoked, their age at the time of data collection was used as the age of initiation. A dummy variable was used to separate these participants from the others and was used in the survival analysis to estimate the hazards of smoking initiation.

Several sociodemographic variables included in the analysis were: age at survey (in years), sex (men/ women), ethnicity (Han/minority), residence (urban/ rural), educational attainment (primary school or less, secondary school, high school or more) and yearly household income (Renminbi (RMB ¥), <5000, 5000-19 999, $\geq 20000$, US $\$ 1=6.25 ¥)$. Ethnic groups were categorised as Han Chinese and ethnic minority because the majority of the population in South-West China is either Han Chinese or small groups of other ethnic minorities. These ethnic minorities follow similar lifestyles and hence were categorised as one group. ${ }^{22}$ Residence was categorised as urban (two county towns: Panlong, and Gejiu) and rural (rural villages in four counties: Luxi, Menglian, Ninglan and Shuifu), based on national criteria. ${ }^{23}$

\section{Statistical analysis}

Hazards of smoking initiation by age: A survival analysis model was used to estimate the hazards of smoking initiation by a single year of age. The hazards of smoking initiation at any given age $(\mathrm{H}(\mathrm{t}))$ were defined as the ratio of the new smokers in the age over the total numbers of non-smokers at the beginning of this age. Therefore, $\mathrm{H}$ (t) provides an estimation of an instantaneous probability of smoking initiation by age.

In the survival modelling analysis, a person who had initiated smoking was coded as a failure, while those who had not yet initiated smoking at the age of the survey were counted as censored. Taking advantages of survival modelling analysis, the age of these participants at the 
Table 1 Demographic characteristics of the participants $(n=4801)$

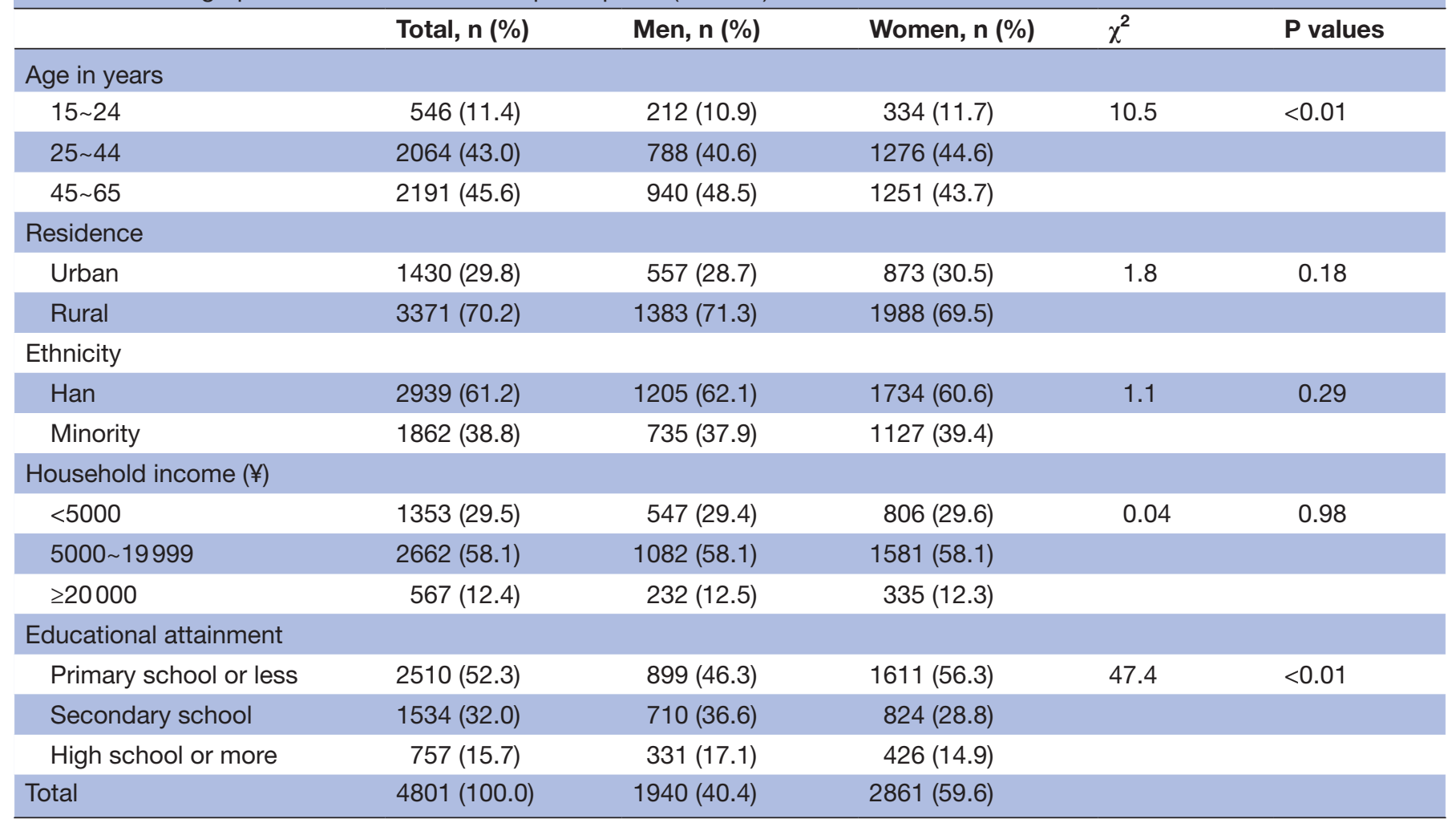

survey time was included for analysis to fully use the information provided by these participants. ${ }^{24}$

Plots of $-\log (\mathrm{S}(\mathrm{t}))$ over age and $\log (-\log (\mathrm{S}(\mathrm{t})))$ against log (age) were used to verify empirically whether the distribution of the hazard of smoking initiation by age follows an exponential or Weibull model. The log-rank test was used to determine the difference of $\mathrm{H}(\mathrm{t})$ in the subgroups. The Proc Lifetest from SAS was used for survival analysis. The life table method was used for the estimation of the hazard of smoking initiation $\mathrm{H}(\mathrm{t})$ and the difference in the estimated $\mathrm{H}(\mathrm{t})$ between subgroups including sex, ethnicity and residence.

Descriptive analysis techniques and $\chi^{2}$ test were used in the study. Demographic characteristics of the study population were presented as percentage. Prevalence of current smoking, lifetime smoking and their 95\% CIs were calculated. $\chi^{2}$ test was used to determine the differences in demographic characteristics and tobacco products use in subgroups. All statistical analyses were performed with SAS Software V.9.2 (SAS Institute, Cary, North Carolina, USA). Two-sided $\mathrm{p}<0.05$ was considered statistically significant.

\section{RESULTS}

Demographic characteristics of the participants are summarised in table 1 . Of the 4801 participants, 1940 were men $(40.4 \%)$ and 2861 were women $(59.6 \%)$. Among the participants, $38.8 \%$ were from ethnic minority and $70.2 \%$ were rural residents. No sex differences were found in ethnicity, residence and income. Men were more educated than women $(p<0.05)$.

Table 2 shows the current and lifetime smoking prevalence $(95 \% \mathrm{CI})$ of the participants. The prevalence rates of current and lifetime smoking for men $(60.4 \%$ and $66.2 \%$, respectively) were significantly higher than those of women $(7.0 \%$ and $5.1 \%$, respectively). Education and income were negatively associated with prevalence of tobacco smoking. Smoking was particularly more prevalent among rural and ethnic minority women.

Table 3 summarises the three types of tobacco products used by the participants. Overall, $80.7 \%$ of the participants smoked cigarettes, $10.8 \%$ smoked pipe tobacco and $8.5 \%$ smoked waterpipe. There was significant sex, ruralurban and ethnic difference in smoking patterns. Men, urban residents and Han Chinese were more likely to smoke cigarettes while others more likely to smoke pipe or waterpipe tobacco.

Results from survival analysis indicated a satisfactory data-model fit. The plots of $-\log (\mathrm{S}(\mathrm{t}))$ over age showed a curved line overall and for subgroups by sex, ethnicity and residence. And the plots of $\log \{-\log (\mathrm{S}(\mathrm{t}))\}$ against $\log$ (age) showed a roughly straight line that passed through the origin overall and for each of the six subgroups. These results indicated that the hazard of smoking initiation for the participants follows a Weibull distribution.

Figure 1 presents the estimated hazards of smoking initiation by age using the survival model: (A) for overall sample and (B) by sex. The youngest age of initiation of smoking was 5 years. Before the age of 12 years, the 
Table 2 Prevalence and $95 \% \mathrm{Cl}$ of current and lifetime smoking $(n=4801)$

\begin{tabular}{|c|c|c|c|c|}
\hline \multirow[b]{2}{*}{ Variable } & \multicolumn{2}{|l|}{ Men } & \multicolumn{2}{|l|}{ Women } \\
\hline & $\begin{array}{l}\text { Current smoking } \\
\%(95 \% \mathrm{Cl})\end{array}$ & $\begin{array}{l}\text { Lifetime smoking } \\
\%(95 \% \mathrm{Cl})\end{array}$ & $\begin{array}{l}\text { Current smoking } \\
\%(95 \% \mathrm{Cl})\end{array}$ & $\begin{array}{l}\text { Lifetime smoking } \\
\%(95 \% \mathrm{Cl})\end{array}$ \\
\hline \multicolumn{5}{|l|}{ Age in years } \\
\hline $15 \sim 24$ & 27.4 (21.4 to 33.4$)$ & 32.1 (25.8 to 38.4 ) & $0.6(0$ to 1.1$)$ & 3.3 (1.4 to 5.2$)$ \\
\hline $25 \sim 44$ & 64.4 (61.1 to 67.8$)$ & 68.8 (65.6 to 72.1$)$ & 5.1 (3.9 to 6.4$)$ & 6.7 (5.4 to 8.0$)$ \\
\hline $45 \sim 65$ & 64.6 (61.6 to 67.7$)$ & 71.7 (68.8 to 74.6 ) & $6.2(4.9$ to 7.6$)$ & $8.2(6.7$ to 9.2$)$ \\
\hline \multicolumn{5}{|l|}{ Residence } \\
\hline Urban & 63.0 (58.9 to 67.0$)$ & 70.6 (66.9 to 74.3$)$ & $1.2(0.4$ to 1.8$)$ & 3.6 (2.3 to 4.8$)$ \\
\hline Rural & 59.4 (56.8 to 62.0 ) & 64.4 (61.9 to 66.8 ) & 6.8 (5.7 to 7.9$)$ & 8.5 (7.2 to 9.7$)$ \\
\hline \multicolumn{5}{|l|}{ Ethnicity } \\
\hline Han & 60.5 (57.7 to 63.2 ) & 67.3 (64.6 to 70.0$)$ & 0.9 (0.4 to 1.4$)$ & 2.9 (2.1 to 3.7$)$ \\
\hline Minority & 60.4 (56.9 to 63.9$)$ & 64.4 (60.8 to 67.8$)$ & 11.5 (9.6 to 13.3$)$ & $13.2(11.2$ to 15.2$)$ \\
\hline \multicolumn{5}{|l|}{ Household income ( $¥)$} \\
\hline$<5000$ & 66.9 (62.8 to 70.8$)$ & 72.0 (68.2 to 75.8$)$ & 7.1 (5.3 to 8.2$)$ & 8.7 (6.7 to 10.6$)$ \\
\hline $5000 \sim$ & 58.7 (55.7 to 61.6$)$ & 64.2 (61.4 to 67.1$)$ & 5.1 (4.0 to 6.1$)$ & 7.2 (5.9 to 8.4$)$ \\
\hline$\geq 20000$ & 53.0 (46.4 to 59.4$)$ & 60.3 (55.0 to 66.6 ) & 2.1 (0.8 to 3.6$)$ & 3.6 (1.6 to 5.6$)$ \\
\hline \multicolumn{5}{|l|}{ Educational attainment } \\
\hline Primary school or less & 65.5 (62.4 to 68.6$)$ & 70.5 (67.5 to 73.5$)$ & 8.1 (6.8 to 9.6$)$ & 9.6 (8.2 to 11.1$)$ \\
\hline Secondary school & 56.3 (52.7 to 60.0 ) & 62.4 (58.8 to 66.0 ) & $0.6(0.1$ to 1.1$)$ & 3.0 (1.8 to 4.2 ) \\
\hline High school or more & 55.5 (50.1 to 60.8$)$ & 62.5 (57.1 to 67.8$)$ & 2.1 (0.7 to 3.5$)$ & 4.5 (2.5 to 6.4$)$ \\
\hline Total & 60.4 (58.2 to 62.6$)$ & 66.2 (64.1 to 68.7$)$ & 5.1 (4.3 to 5.9$)$ & $7.0(6.0$ to 7.9$)$ \\
\hline
\end{tabular}

estimated hazards of smoking initiation among men and women were rather low (less than $0.5 \%$ and $0.05 \%$, respectively). However, from 12 years of age, the hazards began to increase in men and women. From 15 years of age, the increases in hazards accelerated and peaked at age 19 years for men $(21.5 \%)$ and women $(1 \%)$. After 19 years of age, the hazards declined rapidly for both men and women. The log-rank test indicated significant sex differences in the estimated hazards of smoking initiation $\left(\chi^{2}=2045.8, \mathrm{p}<0.01\right)$.

Figure 2 compares the hazards of smoking initiation by age in men between urban and rural residence $(\mathrm{A})$ and between Han Chinese and ethnic minority (B). The age patterns of the estimated hazards of smoking initiation for rural and urban residents and between Han Chinese and ethnic minority were similar to that of the overall pattern as presented in figure 1 . Both the rural-urban and ethnic differences were not statistically significant $\left(\chi^{2}=0.13, p=0.71 ; \chi^{2}=0.83, p=0.36\right)$.

Figure 3 shows urban-rural (A) and Han minority (B) differences of women in the estimated hazards of smoking initiation by age. Figure 3(A) indicated a significantly higher hazard of smoking initiation for rural women than urban women during the age range 15-19 years. Overall

Table 3 Tobacco products used by the current smokers $(n=1317)$

\section{Tobacco products}

\begin{tabular}{|c|c|c|c|c|c|c|}
\hline & \multirow[b]{2}{*}{$\mathbf{N}$} & & \multirow[b]{2}{*}{$\chi^{2}$} & \multirow[b]{2}{*}{$P$ values } \\
\hline & & Cigarette n (\%) & Pipe tobacco n (\%) & Waterpipe n (\%) & & \\
\hline \multicolumn{7}{|l|}{ Sex } \\
\hline Men & 1172 & 1012 (86.3) & 77 (6.6) & $83(7.1)$ & 7.7 & $<0.01$ \\
\hline \multicolumn{7}{|l|}{ Residence } \\
\hline Urban & 360 & 331 (91.9) & $11(3.1)$ & $18(5.0)$ & 10.3 & $<0.01$ \\
\hline \multicolumn{7}{|l|}{ Ethnicity } \\
\hline Han & 744 & $653(87.8)$ & $33(4.4)$ & $58(7.8)$ & 29.2 & $<0.01$ \\
\hline Minority & 573 & $410(71.6)$ & $106(18.5)$ & $57(9.9)$ & & \\
\hline Total & 1317 & 1063 (80.7) & $139(10.6)$ & $115(8.7)$ & & \\
\hline
\end{tabular}


A

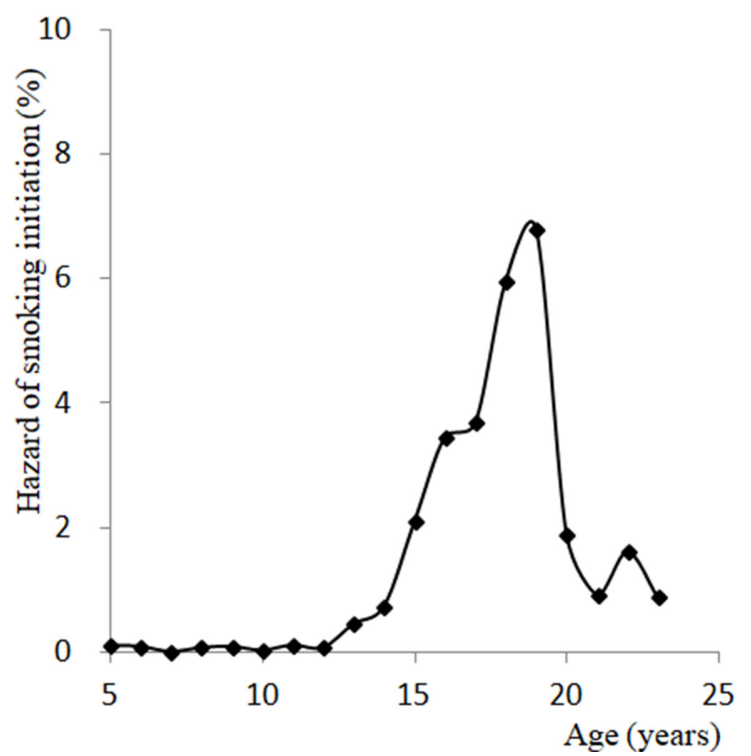

B

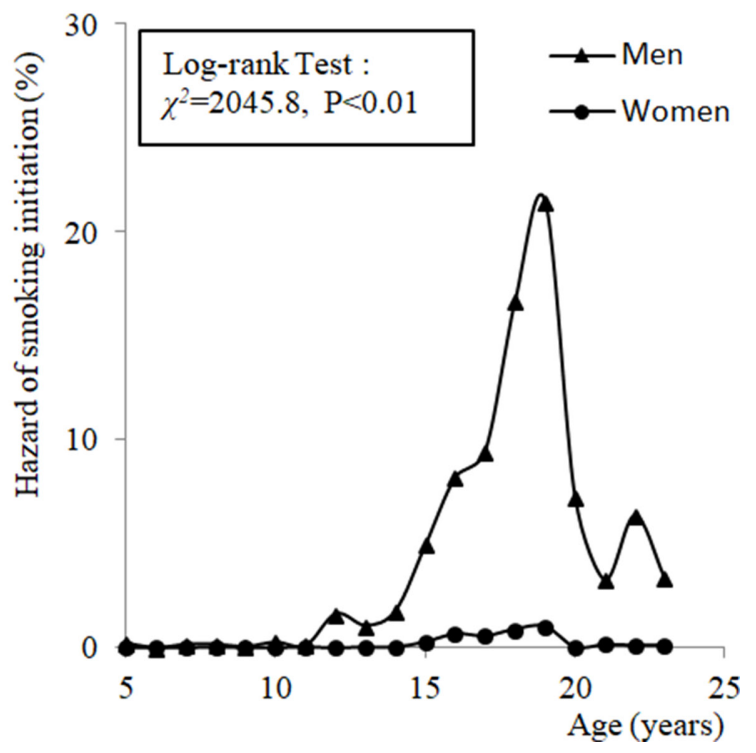

Figure 1 Estimated hazards of smoking initiation by age: (A) overall sample, (B) by sex.

the urban-rural difference was statistically significant $\left(\chi^{2}=44.8, p<0.01\right)$. Figure 3(B) showed that the hazards of smoking initiation were much higher for ethnic minority women than Han Chinese women also during the age range $15-19$ years. From age 20 years, the hazards maintained at a very low level for Han Chinese women but increased suddenly for ethnic minority women. The difference was statistically significant $\left(\chi^{2}=165.2, \mathrm{p}<0.01\right)$.

\section{DISCUSSIONS}

The main findings of this study can be summarised as follows. First, smoking was highly prevalent among men in South-West China. Second, there was a significant difference in the type of tobacco products used depending on their sex, residence and ethnicity. Finally, the hazard of

\section{A}

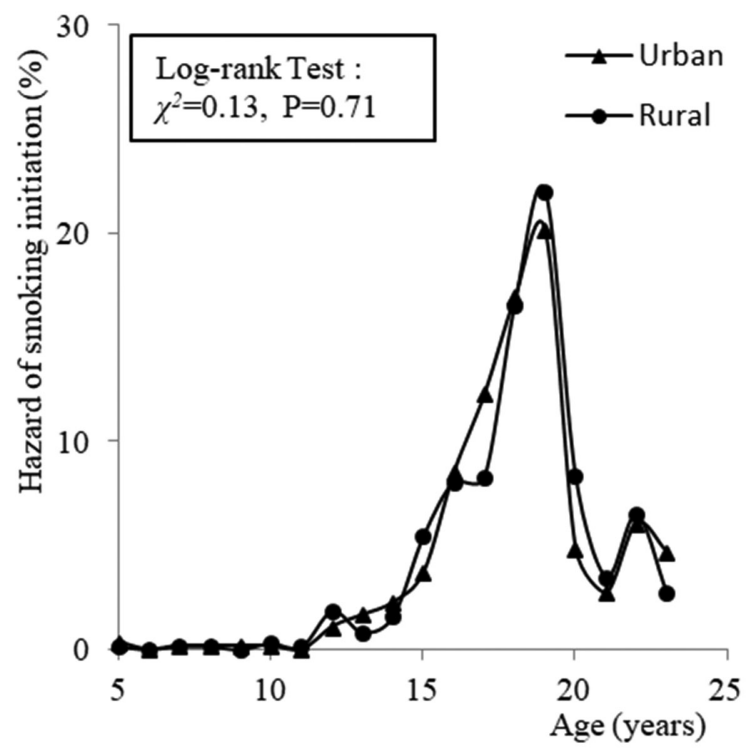

smoking initiation sharply increased among men and women when they were 15-19 years old.

In this study, the overall prevalences of current smoking for men and women are $60.4 \%$ and $5.1 \%$, respectively, which is significantly higher than the national average $\left(51.6 \%\right.$ and $2.9 \%$ for men and women, respectively). ${ }^{4} \mathrm{~A}$ recent study in South-West China indicates that smoking and passive smoking account for $13.1 \%$ of local direct and indirect health costs. ${ }^{25}$ This situation calls for immediate preventive measures that aim towards tobacco control in South-West China. In terms of social determinants of smoking, our findings that men and women with lower education and income are more likely to smoke are consistent with previous findings from studies conducted in China and other developing countries. ${ }^{26}{ }^{27}$ The current

\section{B}

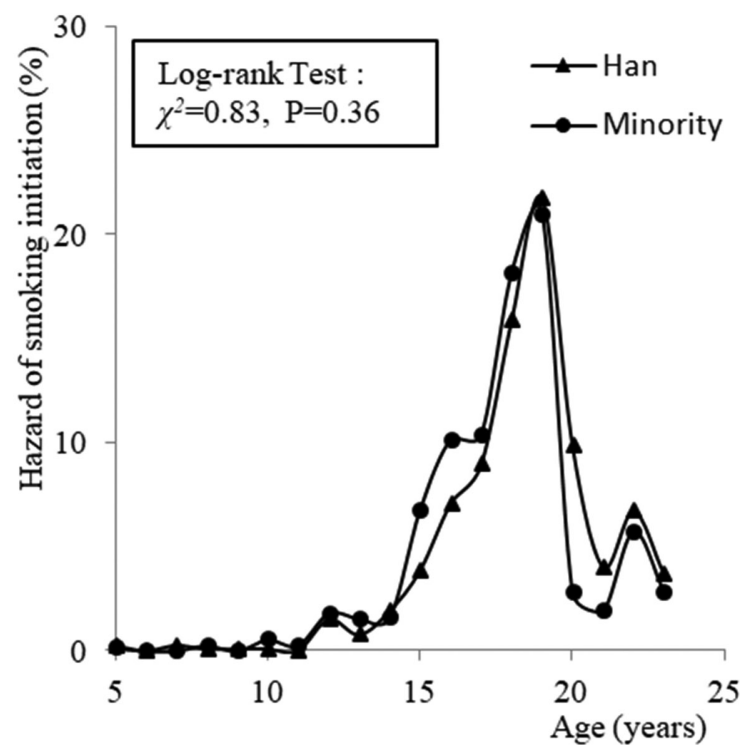

Figure 2 Estimated hazards of smoking initiation by age in men: (A) by residence, (B) by ethnicity. 
A

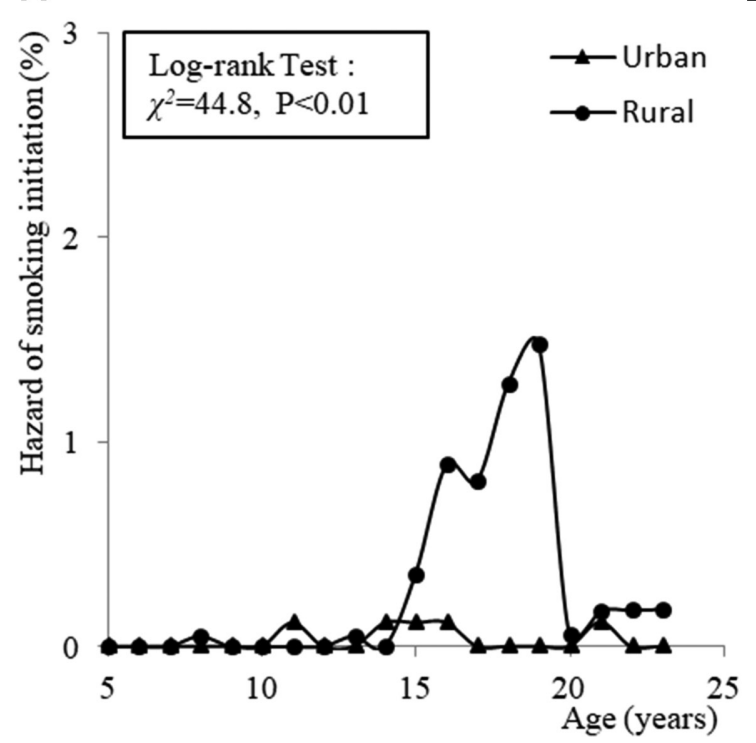

B

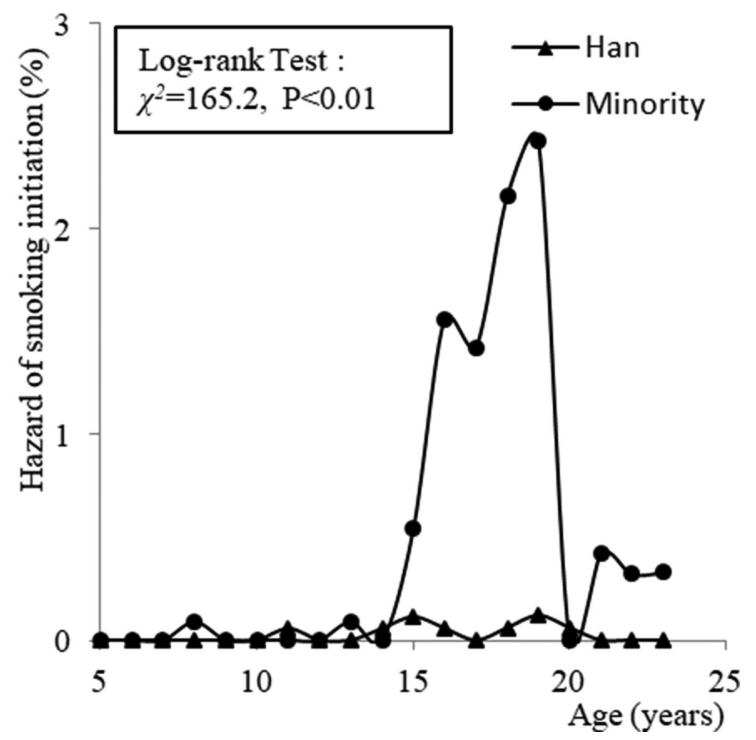

Figure 3 Estimated hazards of smoking initiation by age in women: (A) by residence, (B) by ethnicity.

analysis does not show any significant association between smoking and place of residence or ethnicity among men. However, smoking prevalence was found to be significantly higher among rural $(6.8 \%)$ and ethnic minority women $(11.5 \%)$ as compared with urban $(1.2 \%)$ and Chinese Han women $(0.9 \%)$. One possible reason for the differences could be low educational status and lesser awareness regarding the health risks of tobacco smoking among the rural and minority women in South-West China. ${ }^{728}$ Another reason could be the cultural approval and the acceptance of women's smoking among many ethnic minorities in South-West China. ${ }^{29}$ For example, an earlier study found that smoking prevalence among Dai ethnic women was $5.0 \%$ which is close to the current findings. ${ }^{30}$ Finally, the high smoking prevalence among women in this study compared with other studies from South-West China $(1.3 \%-1.4 \%)^{31} 32$ may also be due to the higher proportion of ethnic minority participants included in this study $(39.4 \%$ vs $23.8 \%)$. The above findings highlight an urgent need to develop and implement women-specific smoking prevention strategies in SouthWest China.

In line with previous studies from China, ${ }^{31}{ }^{33}$ we also found significant differences in the pattern and type of tobacco use by sex, residence and ethnicity. In this study, cigarette is the most popular form of tobacco smoking for men $(86.3 \%)$, whereas pipe tobacco is the most popular form among women $(42.8 \%)$. Rural and minority residents are more likely to use pipe tobacco and waterpipe compared with their urban counterparts. There are several reasons for these differences. First of all, people living in Yunnan Province, situated in rural South-West China, have easier access to tobacco products since tobacco is the main cultivation in most of the counties of Yunnan Province contributing to $40 \%$ of the tobacco production in the China. ${ }^{34}$ Second, pipe tobacco and waterpipe are cheaper compared with cigarettes in areas where tobacco is cultivated, making it a preferred product for the rural population. ${ }^{35}$ Additionally, women usually smoke in their own private circles making it easier to use a waterpipe or pipe tobacco than cigarettes. ${ }^{36}$ However, waterpipe and pipe tobacco contain many of the same toxicants as cigarette, and also have substantial health risks. ${ }^{37}$ Therefore, tobacco control policies need to seriously consider the health risks of using diverse tobacco products and also curtailing the tobacco cultivation in South-West China.

In this study, we identified a peak of smoking initiation from 15 years to 19 years of age, as well as a significant sex difference in the age pattern of smoking initiation similar to the study conducted by Chen $e t$ al in another city located in central China. ${ }^{14}$ Studies have reported that in USA the hazards of smoking initiation peak during the mid-teens (15-16 years old), and there is no significant difference in sex. ${ }^{1124}$ Our findings indicate that men are still the key focus of tobacco control in South-West China, and the relative low hazards of smoking initiation in women should be maintained or decreased. In addition, we found that rural and ethnic minority women were at higher risk of smoking initiation. Yet, a larger examination of the policies and regulations in China has paid little attention to tobacco control in these populations. ${ }^{39} 40$ Previous studies have shown that the determinants of youth smoking range from individual-level factors to broad social influence. ${ }^{41-43}$ The sharp increase of smoking initiation from 15 years of age may be partly explained due to imbalance between physical maturation and cognitive development. ${ }^{44}$ The imbalance many times encourages adolescents to experiment on various risky behaviours such as smoking, to appear grown-up, 'cool' and gain peer acceptance. ${ }^{45}$ Further, 15-19-year-old adolescents are under great pressure from school and family, and they may start using smoking as a method to cope with negative emotions. ${ }^{41}$ Lastly, older adolescents usually have easier access to tobacco products 
than younger adolescents, which is a prerequisite for smoking. ${ }^{46}$

A study conducted in USA showed that a 1-year delay in the age of smoking initiation predicted about 0.7 times less likelihood of being a regular smoker. ${ }^{47}$ Thus, preventing adolescents from taking the first puff is a significant step to achieve reduction of tobacco use among the adult population in the future. ${ }^{3}$ Additionally, existing tobacco control strategies should be implemented more effectively. For example, although tobacco sales have been banned in China since 1999, further actions are urgently needed to effectively enforce the ban regulations to reduce the accessibility of cigarettes to adolescents. ${ }^{48}$ Second, extending and enforcing smoke-free places, have been associated with lower rates of adolescents smoking. ${ }^{49}$ Third, enforce comprehensive bans on all tobacco advertising and educate adolescents that smoking is not a symbol of 'handsome' or independence, but a serious addiction and health risk. Information on the health risks associated with pipe tobacco and waterpipes that are being widely used in South-West China should be disseminated and special emphasis should be given on this issue in local health education. Finally, given the long-standing hazards and complex determinants of smoking initiation, effective interventions for adolescents and young adults should begin from senior elementary school and continue throughout their college life. ${ }^{4250}$

There are several limitations to this study. First of all, the findings reported here are based on a cross-sectional data set with limited ability to determine causal relationships. The age of smoking initiation is based on self-reports, and may therefore be subject to recall bias. Lack of validation of smoking status with nicotine testing may underestimate the prevalence of smoking. Further, since the present findings were based on a random sample from six counties in South-West China, caution is needed to generalise the results to other places within China.

The findings of this study provide important information on the patterns of smoking behaviours among adolescents and young adults which could serve as the foundation to develop and implement effective smoking prevention intervention programmes. Additionally, our study findings highlight the significance of pipe tobacco and waterpipes among women in certain parts of China, thereby pointing to an urgent need for gender-specific education and prevention policies to control the use of these products in those areas.

Acknowledgements The authors thank the participants for their enthusiastic cooperation. The authors also thank the interviewers from local centers for disease control and prevention for their excellent work.

Contributors QZ, BY and ZL contributed to conception, data analysis and article writing. DSV and XC contributed to data interpretation and article revision. XM, JL, YR, JZ and XH contributed to data collection. All authors provided final approval for submission to BMJ Open.

Funding This work was supported by research grants from Health and Family Planning Commission of Yunnan Province, China (2016NS146, 2017NS103).

Disclaimer The funder had no role in study design, data collection, data analysis, data interpretation or writing of the report.
Competing interests None declared.

Patient consent Obtained.

Ethics approval The Institutional Review Board at the Chinese Center for Disease Control and Prevention.

Provenance and peer review Not commissioned; externally peer reviewed.

Data sharing statement For access to the data set, please contact the lead author (counterstriker_zq@163.com).

Open Access This is an Open Access article distributed in accordance with the Creative Commons Attribution Non Commercial (CC BY-NC 4.0) license, which permits others to distribute, remix, adapt, build upon this work non-commercially, and license their derivative works on different terms, provided the original work is properly cited and the use is non-commercial. See: http://creativecommons.org/ licenses/by-nc/4.0/

(C) Article author(s) (or their employer(s) unless otherwise stated in the text of the article) 2018. All rights reserved. No commercial use is permitted unless otherwise expressly granted.

\section{REFERENCES}

1. Jha P, Peto R. Global effects of smoking, of quitting, and of taxing tobacco. N Engl J Med 2014;370:60-8.

2. Yang G, Wang Y, Wu Y, et al. The road to effective tobacco control in China. Lancet 2015;385:1019-28.

3. Chen Z, Peto R, Zhou M, et al. Contrasting male and female trends in tobacco-attributed mortality in China: evidence from successive nationwide prospective cohort studies. Lancet 2015;386:1447-56.

4. Li S, Meng L, Chiolero A, et al. Trends in smoking prevalence and attributable mortality in China, 1991-2011. Prev Med 2016;93:82-7.

5. Jiang $Y$, Li Q, Xiao L, et al. [Epidemic and control on tobacco in China]. Zhonghua Liu Xing Bing Xue Za Zhi 2011;32:1181-7.

6. Li Q, Hsia J, Yang G. Prevalence of smoking in China in 2010. N Engl $J$ Med 2011;364:2469-70.

7. Cai L, Cui W, You D, et al. Socioeconomic variations in nicotine dependence in rural southwest China. BMC Public Health 2015;15:1158.

8. Tang X, Chen X, Li H, et al. Smoking and drinking patterns among residents of Li ethnic minority villages in Hainan, China. Subst Use Misuse 2005;40:687-701.

9. Wu Q, Gao Y, Yang R, et al. Comparative study of differences in behavior and awareness related to smoking among ethnic groups in Dehong Yunnan Province. Modern Preventive Medicine 2016;43:5.

10. Martell BN, Garrett BE, Caraballo RS. Disparities in Adult Cigarette Smoking - United States, 2002-2005 and 2010-2013. MMWR Morb Mortal Wkly Rep 2016;65:753-8.

11. Chen X, Unger JB. Hazards of smoking initiation among Asian American and non-Asian adolescents in California: a survival model analysis. Prev Med 1999;28:589-99.

12. Li L, Feng G, Jiang Y, et al. Prospective predictors of quitting behaviours among adult smokers in six cities in China: findings from the International Tobacco Control (ITC) China Survey. Addiction 2011;106:1335-45.

13. Riggs NR, Chou CP, Li C, et al. Adolescent to emerging adulthood smoking trajectories: when do smoking trajectories diverge, and do they predict early adulthood nicotine dependence? Nicotine Tob Res 2007;9:1147-54.

14. Chen X, Li Y, Unger JB, et al. Hazard of smoking initiation by age among adolescents in Wuhan, China. Prev Med 2001;32:437-45.

15. Chen L, Chen Y, Hao Y, et al. Effectiveness of school-based smoking intervention in middle school students of Linzhi Tibetan and Guangzhou Han ethnicity in China. Addict Behav 2014;39:189-95.

16. Green MJ, Leyland $\mathrm{AH}$, Sweeting $\mathrm{H}$, et al. Socioeconomic position and early adolescent smoking development: evidence from the British Youth Panel Survey (1994-2008). Tob Control 2016;25:203-10.

17. Maggi S, Hertzman $C$, Vaillancourt T. Changes in smoking behaviors from late childhood to adolescence: insights from the Canadian National Longitudinal Survey of Children and Youth. Health Psychol 2007;26:232-40.

18. Wellman RJ, DiFranza JR, Savageau JA, et al. Short term patterns of early smoking acquisition. Tob Control 2004;13:251-7.

19. Zhang L, Cui Y, Wang C, et al. [Survey on status of smoking, passive smoking and quitting smoking in rural areas of the midwestern provinces in China]. Zhonghua Liu Xing Bing Xue Za Zhi 2013;34:137-9. 
20. Zhang J, Ou JX, Bai CX. Tobacco smoking in China: prevalence, disease burden, challenges and future strategies. Respirology 2011;16:1165-72.

21. Nez Henderson P, Kanekar S, Wen Y, et al. Patterns of cigarette smoking initiation in two culturally distinct American Indian tribes. Am J Public Health 2009;99:2020-5.

22. Li BH, Ma J, Wu SS, Ss W, et al. [Prevalence rates of overweight and obesity in Chinese minority students in 2005]. Zhonghua Liu Xing Bing Xue Za Zhi 2009;30:915-8.

23. 2010 YSY. Yunnan Province Statistical Bureau. Beijing: China Statistics Press, 2011.

24. Edelen MO, Tucker JS, Ellickson PL. A discrete time hazards model of smoking initiation among West Coast youth from age 5 to 23. Prev Med 2007;44:52-4.

25. Cai L, Cui W, He J, et al. The economic burden of smoking and secondhand smoke exposure in rural South-West China. J Asthma 2014:51:515-21.

26. Li Z, Yao Y, Han W, et al. Smoking Prevalence and Associated Factors as well as Attitudes and Perceptions towards Tobacco Control in Northeast China. Int J Environ Res Public Health 2015;12:8606-18.

27. Hosseinpoor AR, Parker LA, Tursan d'Espaignet E, et al. Socioeconomic inequality in smoking in low-income and middleincome countries: results from the World Health Survey. PLoS One 2012;7:e42843.

28. Ho MG, Ma S, Chai W, et al. Smoking among rural and urban young women in China. Tob Control 2010;19:13-18.

29. Yuan C. Socialogical anlysis of minority females health and smoking in Yunnan frontier. Journal of Kunming University 2008;19:5.

30. Linghu J, Xiao Y, Yang Y, et al. Smoking Prevalence and Associated Factors Yunnan Province: results from a three county survey. Stait Journal of Preventive Medicine 2005;11:2.

31. Cai L, Wu X, Goyal A, et al. Patterns and socioeconomic influences of tobacco exposure in tobacco cultivating rural areas of Yunnan Province, China. BMC Public Health 2012;12:842.

32. Cai L, Wu X, Goyal A, et al. Multilevel analysis of the determinants of smoking and second-hand smoke exposure in a tobacco-cultivating rural area of southwest China. Tob Control 2013;22(Suppl 2):ii16-ii20.

33. Yang T, Li F, Yang X, et al. Smoking patterns and sociodemographic factors associated with tobacco use among Chinese rural male residents: a descriptive analysis. BMC Public Health 2008;8:248.

34. Luo RJ, Yang WZ, Xiong LR. Flue-cured Tobacco yield and spatial pattern in Yunnan Province. Modern Economic Information 2016;4:3.

35. Rich ZC, Hu M, Xiao S. Gifting and sharing cigarettes in a rural Chinese village: a cross-sectional study. Tob Control 2014;23:496-500.
36. Wang J, Li C, Jia C, et al. Smoking, smoking cessation and tobacco control in rural China: a qualitative study in Shandong Province. BMC Public Health 2014;14:916.

37. Azab M, Khabour OF, Alkaraki AK, et al. Water pipe tobacco smoking among university students in Jordan. Nicotine Tob Res 2010;12:606-12.

38. Primack BA, Walsh M, Bryce C, et al. Water-pipe tobacco smoking among middle and high school students in Arizona. Pediatrics 2009;123:e282-e288.

39. Wan X, Shin SS, Wang Q, et al. Smoking among young rural to urban migrant women in China: a cross-sectional survey. PLoS One 2011;6:e23028

40. Liu S, Zhang M, Yang L, et al. Prevalence and patterns of tobacco smoking among Chinese adult men and women: findings of the 2010 national smoking survey. J Epidemiol Community Health 2017;71:154-61.

41. Guo Q, Unger JB, Azen SP, et al. Cognitive attributions for smoking among adolescents in China. Addict Behav 2010;35:95-101.

42. Wen X, Chen W, Muscat JE, et al. Modifiable family and school environmental factors associated with smoking status among adolescents in Guangzhou, China. Prev Med 2007;45:189-97.

43. Song AV, Morrell HE, Cornell JL, et al. Perceptions of smokingrelated risks and benefits as predictors of adolescent smoking initiation. Am J Public Health 2009;99:487-92.

44. Chen X, Yu B, Lasopa SO, et al. Current patterns of marijuana use initiation by age among US adolescents and emerging adults: implications for intervention. Am J Drug Alcohol Abuse 2017;43:261-70.

45. Chen X, Fang X, Li X, et al. Stay away from tobacco: a pilot trial of a school-based adolescent smoking prevention program in Beijing, China. Nicotine Tob Res 2006;8:227-37.

46. Hawkins SS, Bach N, Baum CF. Impact of Tobacco Control Policies on Adolescent Smoking. J Adolesc Health 2016;58:679-85.

47. Reidpath DD, Ling ML, Wellington $\mathrm{E}$, et al. The relationship between age of smoking initiation and current smoking: an analysis of school surveys in three European countries. Nicotine Tob Res 2013;15:729-33.

48. Wang L, Lu B, Wewers ME, et al. Are retailers compliant with zoning regulations that ban tobacco sales near schools in Changsha, China? Tob Control 2017;26:446-51.

49. Farkas AJ, Gilpin EA, White MM, et al. Association between household and workplace smoking restrictions and adolescent smoking. JAMA 2000;284:717-22.

50. Chen X, Li X, Stanton B, et al. Patterns of cigarette smoking among students from 19 colleges and universities in Jiangsu Province, China: a latent class analysis. Drug Alcohol Depend 2004;76:153-63. 